\title{
Clinicopathological trends of colorectal carcinoma patients in a tertiary cancer centre in Eastern India
}

\author{
Tapas Patra ${ }^{\mathrm{a}}$, Syamsundar Mandal ${ }^{\mathrm{b}}$, Neyaz Alamc, Nabendu Murmu ${ }^{\mathrm{a}, *}$ \\ a Department of Signal Transduction E Biogenic Amines, Chittaranjan National Cancer Institute (CNCI), Kolkata 700026, India \\ b Department of Epidemiology E' Biostatistics, Chittaranjan National Cancer Institute (CNCI), Kolkata 700026, India \\ ${ }^{\mathrm{c}}$ Department of Surgical Oncology, Chittaranjan National Cancer Institute (CNCI), Kolkata 700026, India
}

\section{A R T I C L E IN F O}

\section{Article history:}

Received 24 February 2017

Accepted 22 April 2017

Available online 5 May 2017

\section{Keywords:}

Colorectal Cancer

Mucinous adenocarcinoma

Histopathology

Colectomy

Diabetes

\begin{abstract}
A B S T R A C T
Background: The frequency of colorectal carcinoma is inadequate in India compared to the western world. The carcinoma of colon and rectum is usually disturbing among the individuals of older age group whereas it is less frequent in younger age group. This study was based on age, gender, site of primary tumor and histopathological type of colorectal cancer cases.

Methods: A retrospective study of 420 colorectal carcinoma cases admitted to Chittaranjan National Cancer Institute hospital, Kolkata, India during 2012-2016 was carried out. All the clinicopathological data was collected from the medical records of the patients. The detailed information was entered into tabular sheet and statistical analysis was performed.

Results: During these five years out of total cases in the Department of Surgical Oncology, 5.09\% patients with colorectal carcinoma were admitted for colectomy or hemicolectomy. The percentage of younger age group ( $\leq 40$ year) with colorectal cancer was rise up sharply in context of older age group ( $>60$ year). The ratio of male and female affected in colorectal cancer was $1.6: 1$. Rectum was the most common site $46.2 \%$ among the total cancer lesions. From histopathological data, mucinous adenocarcinoma cases were identified with (23.6\%) high frequency and mostly detected at younger age group (65.7\%). It was found that $18.8 \%$ patients with synchronous liver metastasis and $16.7 \%$ of patients with Type 2 diabetes mellitus were likely to develop colorectal cancer.

Conclusion: The concise overview has documented an increased incidence of colorectal carcinoma patients amongst younger individuals with more aggressive forms like mucinous adenocarcinoma and also development of synchronous liver metastasis.
\end{abstract}

(C) 2017 Published by Elsevier, a division of RELX India, Pvt. Ltd on behalf of INDIACLEN.

\section{Introduction}

Colorectal carcinoma is one of the most frequent malignancies in the world. It is the second foremost cause of cancer mortality in the United States. ${ }^{1-3}$ Hence, colorectal cancer poses a severe concern to public health. Compared to the western world, the incidence rates of colorectal cancer are low in India; but apart from geographical variations, the incidences are rising rapidly in India. ${ }^{4}$ Incidence rate in different subsides varies for age, gender, and race. Colorectal cancer is the third most common cancer in men (746,000 cases, $10.0 \%$ of the total) and the second in women (614,000 cases, $9.2 \%$ of the total) worldwide. Almost $55 \%$ of the

\footnotetext{
* Corresponding author at: Department of Signal Transduction \& Biogenic Amines, Chittaranjan National Cancer Institute, 37, S.P. Mukherjee Road, Kolkata 700026, India.

E-mail addresses: nabendu.murmu@cnci.org.in, nabendu64@gmail.com (N. Murmu).
}

cases occur in more developed regions. There is wide geographical variation in incidence across the world and the geographical patterns are very similar in men and women. ${ }^{5}$ The world's two most populous countries, China and India, have relatively low incidence rates of 14.2 and 6.1 cases per 100,000 men and women, respectively. But as their economies have developed, their incidence of colorectal cancer has increased. ${ }^{6}$ Generally, colorectal carcinoma is thought to be a malignancy that primarily occurs in patients older than 50 years of age ${ }^{7}$; likelihood the disease is an unusual in patients under 40 years of age. It has been estimated that between 2 and $3 \%$ of colorectal cancers occur in patients younger than the age of 40 years. $^{8}$ However, current studies suggested that an increased incidence of colorectal cancers in younger age group in India as well as all over the world. 9,10

Colorectal cancer is a malignant neoplasm arising from the lining of the mucosa of the colon and rectum. It develops by a multistep process that analyzed can be influenced by hereditary or genetic and environmental or acquired factors. An individual with 
a history of adenomatous polyps or inflammatory bowel disease has an increased risk of developing colorectal cancer compared to an individual with no history of either. ${ }^{11,12}$ This type of cancer cells may in the long run multiply to regional lymph nodes and later to more distant lymph nodes and in the other organs. The treatment, prognosis and survival rate largely depends on the stage of disease at diagnosis. Screening for colorectal cancer is particularly effective. Screening can prevent cancer from occurring as it can detect adenomatous polyps that can be successfully removed. ${ }^{13}$ Treatment for colorectal cancer varies by tumor location and stage at diagnosis. Depending upon the stage of the disease, the patient undergoes multimodal treatment, surgery, chemotherapy, radiotherapy and hormonal therapy. Surgical removal of tumor and nearby lymph nodes is mainstay of treatment for early stage of colorectal cancer. However, with a potentially curative surgery alone, up to $50 \%$ patients will ultimately relapse and die of metastatic disease. ${ }^{14}$

Only a few studies from India retrospectively reviewed the incidences of colorectal cancer. Although exact incidence rate cannot be provided by a hospital-based study, the information would be useful in showing patterns of malignancies in our region. This study is designed to describe the distribution of the colorectal carcinoma while considering age, gender, site of tumor, tumor pathology and other related diseases in a retrospective fashion.

\section{Methodology}

A retrospective study was conducted at Chittaranjan National Cancer Institute, Kolkata, a Regional Cancer Centre of Eastern India. The patients with colorectal malignancy who were underwent colectomy or hemicolectomy in the Department of Surgical Oncology during the period January 2012 to July 2016, were included in this study. All the cases were histopathologically confirmed. The information was collected from the medical records of the patients. A total of 420 patients were included in the study. The survival pattern of the patients was not included in the study.

All the data were entered into Microsoft Office Excel 2007 spreadsheet. Statistical Analysis was performed with help of EPI INFO (TM) 3.5.4 from the Centers for Disease Control and Prevention (CDC). ${ }^{15}$ Descriptive statistical analysis was performed to calculate the means with corresponding standard deviations (SD). Test of proportion was used to find the Standard Normal Deviate $(Z)$ to compare the difference proportions and Chi-square $\left(\chi^{2}\right)$ test was performed to find the associations. Odds Ratio (OR) with $95 \%$ confidence interval $(\mathrm{CI})$ had been calculated to find the risk factors. $\mathrm{P} \leq 0.05$ was taken to be statistically significant.

\section{Results and Discussion}

During this study period, a total number of 8251 cancer patients were attended in the Department of Surgical Oncology out of which 420 (5.09\%) patients were diagnosed with colorectal carcinoma. The year wise distribution of these 420 colorectal cases (Table 1) during the period was 92 (4.40\%) in 2012, 88 (4.84\%)

Table 1

Year-wise distribution of colorectal incidences.

\begin{tabular}{llll}
\hline Year & Total number of cases & Colorectal cases & Percentage \\
\hline 2012 & 2092 & 92 & $4.40 \%$ \\
2013 & 1818 & 88 & $4.84 \%$ \\
2014 & 2589 & 135 & $5.21 \%$ \\
2015 & 532 & 31 & $5.83 \%$ \\
2016 & 1220 & 74 & $6.07 \%$ \\
Total & 8251 & 420 & $5.09 \%$ \\
\hline
\end{tabular}

in 2013, 135 (5.21\%) in 2014, 31(5.83\%) in 2015 and 74 (6.07\%) in 2016. From the year wise distribution, it showed gradually rise up the colorectal cases but it was not statistically significant $(Z=0.64$; $\mathrm{p}=0.51$ ). Both urban and rural populations of this part of India were attended to this Cancer hospital. The number of 221 (52.6\%) and 199 (47.4\%) patients attended from rural and urban area, respectively. No significant difference was found between the proportion of patients from urban and rural area $(Z=0.84$; $p=0.39$ ). But overall, the colorectal carcinoma was distributed slightly higher among urban people rather than rural people. Changes in food habits or much exposes in environmental pollution of urbanized people might be more prone to this disease. From all diagnosed colorectal incidences, $77.1 \%, 21.0 \%$ and $1.9 \%$ were Hindu, Muslim and other religion; respectively $(Z=7.92$; $\mathrm{p}<0.001)$. These percentages of religious differentiation were forthwith coming from total patient population included in this study.

In total, 420 colorectal cancer patients, ages between 15 to 89 years were analyzed. All the patients divided into three age groups represented (Fig. 1 ) as younger age group ( $\leq 40$ year), mid age group (41-60 year) and older age group ( $>60$ year). From the analysis, it showed that the percentage of younger age group affected in colorectal cancer was inclined whereas the percentage of older individual was declined. The year wise mean age of the colorectal patients was also decreased as follow $49.91 \pm 15.23$ in $2012,49.06 \pm 16.30$ in $2013,48.16 \pm 15.69$ in $2014,47.16 \pm 13.58$ in 2015 and $45.97 \pm 14.74$ in 2016 (Table 2). Generally, incidences of colorectal cancer ascended sharply after the age of 45 years, and $90 \%$ of cases occur in persons over the age of 50 years ${ }^{16,17}$ but its reported incidences among patients of 20-40 years of age increased by $17-20 \%$ now-a-days. ${ }^{18}$ Several studies in India also reported that incidences of colorectal cancer in younger individuals escalated in recent years. ${ }^{19,20}$ This study is also clearly indicated that the percentage of younger colorectal carcinoma patients is rising at the eastern part of India. The exact reasons behind these outcomes are still not clear. However, it is assumed that the early onset colorectal cancer may be the consequence of genetic mutation. Besides, several other factors like intake of excess alcohol, junk foods, uses of tobacco, lack of exercise, etc have potential risk for such observation.

In the retrospective study group, there were 257 (61.2\%) male and $163(38.8 \%)$ female. Thus the proportion of male was significantly higher than that of females $(Z=3.11 ; p=0.002)$. The ratio of male and female (Male:Female) was 1.6:1. These data suggested that female contributed less to observed colorectal

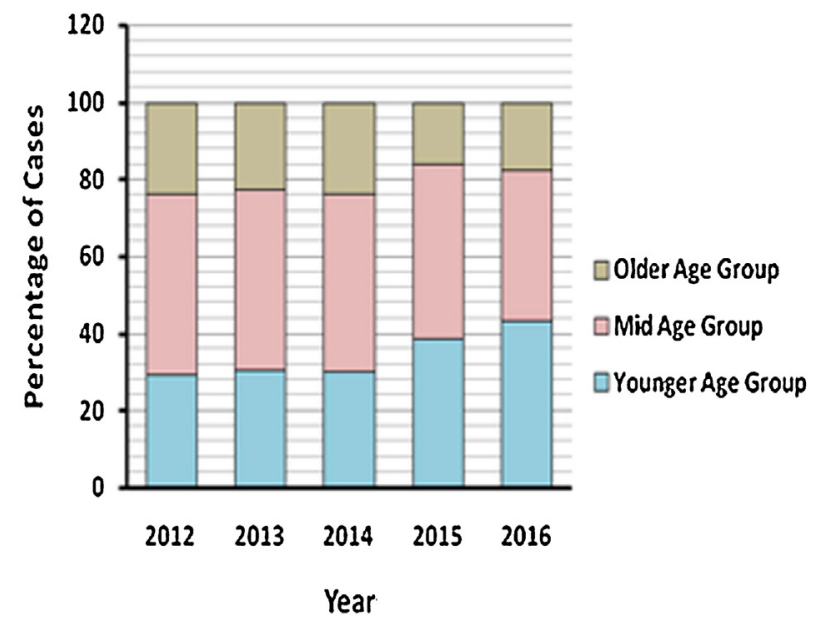

Fig. 1. Year-wise distribution of different age groups. 
Table 2

Year wise mean age distribution of colorectal patients.

\begin{tabular}{llll}
\hline Year & Mean \pm SD & Median & Range \\
\hline $2012(n=92)$ & $49.91 \pm 15.23$ & 49.5 & $22-89$ \\
$2013(n=88)$ & $49.06 \pm 16.30$ & 50.0 & $18-86$ \\
$2014(n=135)$ & $48.16 \pm 15.69$ & 46.0 & $18-82$ \\
$2015(n=31)$ & $47.16 \pm 13.58$ & 49.0 & $21-77$ \\
$2016(n=74)$ & $45.97 \pm 14.74$ & 45.0 & $15-78$ \\
\hline
\end{tabular}

Table 3

Anatomical position of colorectal tumors according to gender basis.

\begin{tabular}{lllll}
\hline Anatomical position & Frequency (\%) & Gender (\%) & \\
\cline { 3 - 5 } & & Male & Female & Male:Female \\
\hline Ceacum & $21(5.0 \%)$ & $13(5.1 \%)$ & $8(4.9 \%)$ & $1.6: 1$ \\
Ascending colon & $44(10.5 \%)$ & $27(10.9 \%)$ & $17(10.4 \%)$ & $1.6: 1$ \\
Transverse colon & $45(10.7 \%)$ & $26(10.1 \%)$ & $19(11.7 \%)$ & $1.4: 1$ \\
Descending colon & $44(10.5 \%)$ & $23(8.9 \%)$ & $21(12.9 \%)$ & $1.1: 1$ \\
Sigmoid colon & $27(6.4 \%)$ & $14(5.4 \%)$ & $13(8.0 \%)$ & $1.1: 1$ \\
Rectum & $194(46.2 \%)$ & $126(49.0 \%)$ & $68(41.7 \%)$ & $1.9: 1$ \\
\hline
\end{tabular}

carcinoma than male. So the sex might influence in the increasing incidences of colorectal cancer.

Colorectal tumors were not uniformly distributed through the large bowel. The anatomical distributions of the colorectal tumor according to the gender difference were represented in (Table 3 ). Rectum was the most common site $46.2 \%$ among the total cancer lesions. The site of the tumor location was found to be significantly higher at rectum $(\mathrm{Z}=2.23 ; \mathrm{p}=0.025)$. Data suggested that male patients with colorectal tumors in rectum were predominant $(49 \%)$ and the ratio of male and female (Male:Female) was with colorectal tumors in rectum 1.9:1. Chi-square $\left(\chi^{2}\right)$ test showed that $\left(\chi^{2}=10.13\right)$ there was no significant association between gender and other anatomical position of colorectal tumors $(p=0.42)$. Thus all the other anatomical positions of cancer were almost evenly distributed among males and females. However, changes in metabolism such as excess bile salt production or intake of low fiber diets might account for the increase in incidence of the rectal cancers. ${ }^{21}$ Another possible explanation for these observations is that it might be because of increased availability of colonoscopy for diagnosis. The trends of tumor's anatomical location for either gender helped for clinical investigation.

Histopathological data from a total number of patients with colorectal carcinoma were collected and analyzed. This study reported that the more aggressive histology of tumors in younger patients with colorectal carcinoma. From Table 4, most of the tumors (56.8\%) encountered adenocarcinoma and they were subdivided into three grades- well differentiated (9.5\%), moderately differentiated (18.3\%) and poorly differentiated (29\%) adenocarcinoma. From this data set, several other malignancies were recognized at small frequency like tubular adenoma (5.7\%),
Table 5

Representation of associated other GI problems with colorectal cases.

\begin{tabular}{llll}
\hline Associated GI problems & $\begin{array}{l}\text { Frequency } \\
(\%)\end{array}$ & Colonic region(\%) & Rectal region (\%) \\
\hline Liver Metastasis & $79(18.8 \%)$ & $43(54.4 \%)$ & $31(39.2 \%)$ \\
Hepatomegaly & $28(6.7 \%)$ & $8(28.6 \%)$ & $13(46.4 \%)$ \\
Ascitis & $21(5.0 \%)$ & $11(52.4 \%)$ & $7(33.3 \%)$ \\
Gastric Cancer & $4(1.0 \%)$ & $3(75.0 \%)$ & $1(25.0 \%)$ \\
\hline
\end{tabular}

squamous cell carcinoma (5\%), lymphoma (2.1\%) and other types (5\%). However, mucinous adenocarcinoma cases were identified with high frequency about $23.6 \%$ of total cases (Table 4 ). This histopathological data were further correlated with three different age groups- younger age group ( $\leq 40$ year), mid age group (4160 year) and older age group ( $>60$ year). The data showed that the adenocarcinoma was indentified majorly in mid age group whereas other types of adenocarcinoma were distributed almost equally through all age groups. Interestingly, the mucinous adenocarcinoma was predominantly isolated at younger age group $(65.7 \%)$ (Table 4$)$. Chi-square $\left(\chi^{2}\right)$ test showed that $\left(\chi^{2}=79.75\right)$ there was significant association between age and type of carcinoma of the patients $(\mathrm{p}<0.001)$. Mucinous adenocarcinoma is a histologic subtype constituting $11-15 \%$ of colorectal carcinoma. ${ }^{22}$ All the cancers other than mucinous adenocarcinoma were significantly more prevalent among the middle aged and older patients and mucinous adenocarcinoma was more prevalent among the young patients. Tumor microsatellite instability has been identified of the genetic basis in most of the younger patients with colorectal carcinoma. The tumor microsatellite instability was suggested for those younger individuals to have a risk for hereditary non-polyposis colorectal cancer like mucinous adenocarcinoma. ${ }^{23}$ It has been suggested a much higher rate in younger patients with mucinous adenocarcinoma due to more rapid progression of lymphatic metastasis.

The associated other GI problems with these colorectal cancer cases were represented at Table 5.79 (18.8\%) with synchronous liver metastasis, 28 (6.7\%) with hepatomegaly, 21 (5.0\%) with ascitis and $4(1.0 \%)$ with gastric cancer associated with colorectal cases were admitted at the time of surgery. For all incidences of synchronous liver metastasis with colorectal carcinoma were $54.4 \%$ in colonic region and $39.2 \%$ in rectal region. Corrected Chisquare $\left(\chi^{2}\right)$ test showed that $\left(\chi^{2}=2.17\right)$ there was no significant association between associated GI problems and region of cancer of the patients $(\mathrm{p}=0.53)$. However, proportion of liver metastasis was significantly higher in colonic region as compared to rectal region $(Z=2.12 ; p=0.03)$. In this study, carcinoma in colonic region led significantly with synchronous liver metastasis than rectal region. Higher stages of carcinoma in colonic region could be based on the venous drainage directly. Further, adhesive interaction with the endothelial cells of the liver is another important step in liver metastasis. ${ }^{24,25}$ The observation indicates that venous infiltration of colorectal patients seems to be important for development of

Table 4

Histopathological distribution of colorectal tumors with different age groups

\begin{tabular}{|c|c|c|c|c|}
\hline \multirow[t]{2}{*}{ Type of carcinoma } & \multirow[t]{2}{*}{ Frequency (\%) } & \multicolumn{3}{|c|}{ Different age groups (\%) } \\
\hline & & Younger & Mid & Older \\
\hline Poorly Differentiated Adenocarcinoma & $122(29.0 \%)$ & $29(20.9 \%)$ & $64(33.9 \%)$ & $29(31.5 \%)$ \\
\hline Moderately Differentiated Adenocarcinoma & $77(18.3 \%)$ & $12(8.6 \%)$ & $43(22.5 \%)$ & $22(23.9 \%)$ \\
\hline Well Differentiated Adenocarcinoma & $40(9.5 \%)$ & $10(7.2 \%)$ & $19(10.1 \%)$ & $11(12.0 \%)$ \\
\hline Tubular Adenoma & $24(5.7 \%)$ & $10(7.2 \%)$ & $12(6.3 \%)$ & $2(2.2 \%)$ \\
\hline Squamous Cell Carcinoma & $21(5.0 \%)$ & $4(2.9 \%)$ & $9(4.8 \%)$ & $8(8.7 \%)$ \\
\hline Lymphoma & $9(2.1 \%)$ & $2(1.4 \%)$ & $4(2.1 \%)$ & $3(3.3 \%)$ \\
\hline Mucinous Adenocarcinoma & $99(23.6 \%)$ & $65(46.8 \%)$ & $25(13.2 \%)$ & $9(9.8 \%)$ \\
\hline Other types & $28(6.7 \%)$ & $7(5.0 \%)$ & $13(6.9 \%)$ & $8(8.7 \%)$ \\
\hline
\end{tabular}




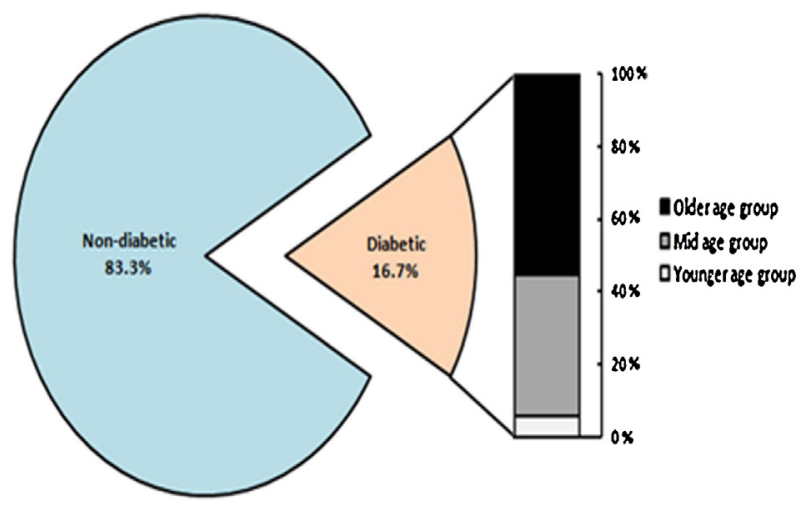

Fig. 2. Graphical representation of colorectal patients with diabetes linked with age groups.

synchronous liver metastasis. Further studies are necessary to investigate the impact of venous infiltration on long-term survival.

A statistical significant association between type 2 diabetes mellitus and the incidence of colorectal cancer was well established. $^{26,27}$ This retrospective study recognized that from 420 colorectal patients, 70 (16.7\%) had type 2 diabetes mellitus. It was found that $55.7 \%$ of patients with diabetes were likely to develop colorectal cancer at an older age group (>60 years), $38.6 \%$ was mid age group (41-60 years) and fewer patients about $5.7 \%$ with diabetes were diagnosed with colorectal cancer at the younger age group ( $\leq 40$ years) (Fig. 2). Proportion of older age group was significantly higher than that of mid and younger age group $(Z=2.40 ; p=0.015)$. The patients suffered for long time in hyperglycimic condition might promote cancer cell proliferation by activation of insulin-like growth factor 1 mediated pathways in which tumor cells seemed to over express insulin-like growth factor 1 receptor and received long-term proliferation signals, likely increasing tumor recurrence and progression. ${ }^{28,29}$ Such data tends to speculate that there is a potential role of diabetes in colorectal carcinoma progression. Apart from diabetes, high body mass index (BMI) or obesity is strongly associated with colorectal cancer progression. The literature suggests that around $9-15 \%$ of colorectal cancer cases have been attributed to overweight and obesity in United States and Europe. ${ }^{30,31}$ In Indian scenario, a very few information has been available regarding on obesity or diabetes in relation with colorectal cancer. However, the current study has also such limitation to provide the information regarding the BMI status of those colorectal cancer patients. It is strongly recommended that this kind of physiological parameters should be included into our hospital registry for future to improve the colorectal cancer management.

\section{Conclusion}

This retrospective observational analysis pointed out a number of significant outcomes. An increased incidence of colorectal carcinoma patients amongst younger individuals in Eastern zone of India was documented in this study. Mucinous adenocarcinoma was highlighted with more aggressive forms and also development of synchronous liver metastasis. These outcomes might play an important role in colorectal disease management in near future. Keeping in mind that this study had some limitations, it would help to reduce the burden of the disease multi-sectorial approach and evidence based strategies aiming at early detection and effective management of colorectal carcinoma.

\section{Conflict of interest}

The authors of the manuscript do not have any conflicts of interest.

\section{Acknowledgements}

Tapas Patra is thankful to Indian Council of Medical Research, India for his ICMR Research Associate Fellowship (Ref. No. 3/2/3/ 313/2015-NCD-III). Nabendu Murmu sincerely thanks to Dr. Tapas Maji, Director, Chittaranjan National Cancer Institute (CNCI), Kolkata, India for his active support.

\section{References}

1. Ferlay J, Shin HR, Bray F, Forman D, Mathers C, Parkin DM. Estimates of worldwide burden of cancer in 2008: GLOBOCAN 2008. Int J Cancer. 2010;127:2893-2917.

2. Ferlay J, Autier P, Boniol M, Heanue M, Colombet M, Boyle P. Estimates of the cancer incidence and mortality in Europe in 2006. Ann Oncol. 2007;18(3):581592.

3. Jemal A, Siegel R, Ward E, Murray T, Xu J, Thun MJ. Cancer statistics 2007. CA Cancer J Clin. 2007:57:43-66.

4. Mohandas KM, Desai DC. Epidemiology of digestive tract cancers in India. V. Large and small bowel. Indian J Gastroenterol. 1999;18:118-121.

5. GLOBOCAN. Estimated Cancer Incidence, Mortality and Prevalence Worldwide in 2012; 2012. http://globocan.iarc.fr.

6. Holmes D. A disease of growth. Nature. 2015;521:S3.

7. Walton WW, Hagihara PG, Griffen WO. Colorectal adenocarcinoma in patients less than 40 years old. Dis Colon Rectum. 1975:19:529-534.

8. O'Connell JB, Maggard MA, Livingston EH, Yo CK. Colorectal cancer in the young. Am J Surg. 2004;187:343-348.

9. Pal M. Proportionate increase in incidence of colorectal cancer at an age below 40 years: an observation. J Cancer Res Ther. 2006;2:97-99.

10. Kalwar A, Nirban RK, Kapoor A, Narayan S, Kumar N, Maharia S. Five year aurvival analysis of colon cancer: a retrospective study. J Gastroenterol Hepato Res. 2013;2(12):929-933.

11. Haskell CM. Cancer treatment. Philadelphia: W.B. Saunders Company: 2001:704-705.

12. Haggar FA, Boushey RP. Colorectal cancer epidemiology: incidence, mortality, survival, and risk factors. Clin Colon Rectal Surg. 2009;22(4):191-197.

13. Rex DK, Eid E. Considerations regarding the present and future roles of colonoscopy in colorectal cancer prevention. Clin Gastroenterol Hepatol. 2008;6 (5):506-514.

14. Obrand DI, Gordon PH. Incidence and patterns of recurrence following curative resection for colorectal carcinoma. Dis Colon Rectum. 1997;40:15-24.

15. Centers for Disease Control and Prevention: Epi Info (TM) 3.5.4; 2017. Available from https://wwwn.cdc.gov/epiinfo/html/prevVersion.htm.

16. Edwards BK, Ward E, Kohler BA, et al. Annual report to the nation on the status of cancer: 1975-2006, featuring colorectal cancer trends and impact of interventions (risk factors, screening, and treatment) to reduce future rates. Cancer. 2010;116(3):544-573.

17. Pignone M, Rich M, Teutsch SM, Berg AO, Lohr KN. Screening for colorectal cancer in adults at average risk: a summary of the evidence for the U.S preventive services task force. Ann Intern Med. 2002;137(2):132-141.

18. Bailey CE, Hu CY, You YN, et al. Increasing disparities in age-related incidence of colon and rectal cancer in the United States: 1975-2010. JAMA Surg. 2015;150(1):17-22.

19. Laskar RS, Talukdar FR, Mondal R, Kannan R, Ghosh SK. High frequency of young age rectal cancer in a tertiary care centre of southern Assam, North East India. Indian J Med Res. 2014;139:314-318.

20. Sudarshan V, Hussain N, Gahine R, Mourya J. Colorectal cancer in young adults in a tertiary care hospital in Chhattisgarh: Raipur. Indian J Cancer. 2015;50 (4):337-340.

21. Wei EK, Giovannucci E, Wu K. Comparison risk factors for colon and rectal cancer. Int J Cancer. 2004;108:433-442.

22. Green JB, Timmcke AE, Mitchell WT. Mucinous carcinoma-just another colon cancer. Dis Colon Rectum. 1993:36:49-54.

23. Kakar S, Aksoy S, Burgart LJ, Smyrk TC. Mucinous carcinoma of the colon: correlation of loss of mismatch repair enzymes with clinicopathologic features and survival. Modern Pathol. 2014;17:696-700.

24. Sugarbaker $\mathrm{PH}$. Metastatic inefficiency: the scientific basis for resection of liver metastases from colorectal cancer. J Surg Oncol Suppl. 1993;3:158-160.

25. Pantel K, Cote RJ, Fodstad O. Detection and clinical importance of micrometastatic disease. J Natl Cancer Inst. 1999;91:1113-1114.

26. Yuhara H, Steinmaus C, Cohen SE, Corley DA, Tei Y, Buffler PA. Is diabetes mellitus an independent risk factor for colon cancer and rectal cancer. Am J Gastroenterol. 2011;106:1911-1921.

27. De Bruijn KM, Arends LR, Hansen BE, Leeflang S, Ruiter R, van Eijck $\mathrm{CH}$. Systematic review and meta-analysis of the association between diabetes 
mellitus and incidence and mortality in breast and colorectal cancer. Br J Surg. 2013;100:1421-1429.

28. Landriscina M, Esposito F. Insulin resistant conditions: a favorable milieu for aggressive drug-resistant malignancies. J Gastrointest Oncol. 2011;2:11-12.

29. Richardson LC, Pollack LA. Therapy insight: influence of type 2 diabetes on the development, treatment and outcomes of cancer. Nat Clin Pract Oncol. 2005;2:48-53.
30. Kendall KA, Lee E, Zuckerman IH. Obesity Status and Colorectal Cancer Screening in the United States. J Obesity. 2013;2013:1-5.

31. Bardou M, Barkun AN, Martel M. Obesity and colorectal cancer. Gut. 2013;62:933-947. 